\title{
Changing Paradigms for Liver Resection of Colorectal Metastases
}

\author{
Nancy E. Kemeny, MD \\ Memorial Sloan-Kettering Cancer Center, New York, NY
}

Prometheus gave mankind wisdom and then suffered the consequences; his liver was eaten each night by eagles and regenerated each day. Surgeons educated by this tale have been resecting liver tumors for years and seeing improvement in patients' survival. The criteria for liver resection in patients with metastatic colorectal cancer have undergone a metamorphosis over the last 50 years with even broader boundaries. In Viganò et al.'s ${ }^{1}$ article in this issue of the Annals of Surgical Oncology, another potential barrier to liver resection may have been lifted. They report that even for patients whose tumor progresses on chemotherapy, there is benefit from hepatic resection. Previous reports of resection in patients with tumor progression have had poor results. ${ }^{2,3}$ Some of the studies may have been too small or had inadequate long-term follow-up. One such report initially described poor results, but on further follow-up and with inclusion of more patients, the authors concluded that there was no difference in survival after liver resection between those whose tumor responded or progressed after neoadjuvant chemotherapy. This may reflect a cautionary tale about retrospective studies that are too small or do not report long-term follow-up. The strength of this report is that it is a large multi-institutional study. ${ }^{1}$ Of the 2,143 patients undergoing hepatic resection, 176 patients experienced tumor progression while on systemic neoadjuvant chemotherapy and still had a $35 \% 5$-year survival. However, since the median follow-up is only 27 months, and most patients in the study were entered after 2006 with data collection stopping in 2010, the 5-year survival is only a projected number. If these results hold up after longer follow-up, Viganò et al.'s study would provide strong support for the use of regional therapy, in this case, hepatic

(C) Society of Surgical Oncology 2012

Published Online: 3 July 2012

N. E. Kemeny, MD

e-mail: kemenyn@mskcc.org resection, in patients with hepatic-only colorectal metastases. An MSKCC study, looking at the question of responders versus nonresponders to chemotherapy prior to liver resection reported no difference in survival in the two groups (59 vs 61 months for the responders vs progression, respectively), with a follow-up time of 63 months. ${ }^{4}$ The MSKCC study was a single-institution study where $80 \%$ of patients received postoperative (postop) therapy and $40 \%$ postop hepatic arterial infusion (HAI). The patients whose tumor progressed in the MSKCC study were more likely to have positive margins when undergoing liver resection, a factor not reviewed in the Viganò study. Viganò's report also stated that poor-risk patients (more than three metastases, lesions greater than $5 \mathrm{~cm}$, or those with CEA higher than $200 \mathrm{ng} / \mathrm{ml}$ ) should be treated with further chemotherapy prior to consideration of hepatic resection.

Is further systemic chemotherapy useful? Second-line systemic chemotherapy has a low response rate averaging $20 \%$ (range $11-35 \%$ ). ${ }^{5}$ The median survival from starting second line treatment is about 11 months (range 9-14 months). ${ }^{5}$ In Viganò et al.'s analysis, patients who progressed on chemotherapy with one negative factor such as more than three liver metastases have a $29.9 \% 5$-year survival when they undergo hepatic resection. The chances of being alive at even 3 years with further systemic therapy if a patient has tumor progression on first-line systemic chemotherapy and has poor risk factors is less than $1 \%$. Use of regional therapy with HAI after progression on systemic therapy may be a more useful approach. Using HAI oxaliplatin and systemic fluorouracil/leucovorin (FU/ LV), Ducreux et al. ${ }^{6}$ observed a $64 \%$ response rate in a group of patients where $81 \%$ had not responded to prior systemic chemotherapy. At MSKCC, patients with unresectable disease who had received previous systemic chemotherapy and then received HAI-FUDR/dexamethasone and systemic (SYS) oxaliplatin/irinotecan had a tumor response rate of $85 \%$ with a median survival of 35 months from the time of initiation of $\mathrm{HAI}^{7}{ }^{7}$ The major toxicities of 
HAI therapy are gastrointestinal and hepatic. ${ }^{26}$ Duodenal ulcers can occur related to missed perfusions. Biliary problems including biliary sclerous that occurs in $6 \%$ of patients (29 of 475) at MSKCC, can occur due to perfusion of biliary ducts. ${ }^{8}$ Higher levels have been reported in other institutions such as $23 \%$ for biliary sclerosis in a French study. ${ }^{9}$

\section{WHAT CAN WE OFFER PATIENTS WHO HAVE POOR RISK FACTORS?}

Patients with poor risk factors tend to do worse whether they are responding or progressing as pointed out in this report where patients with $>3$ metastases had a significantly worse survival. Nordlinger et al. ${ }^{10}$ first described a scoring system that separated patients who had liver resections to 2-year survivals of $79 \%$ versus $43 \%$, if scores were $0-2$ or 5-7, respectively. At MSKCC, a clinical risk score including one point for each risk factor (node status of primary, disease-free interval from primary to liver metastases $<12$ months, number of tumors $>1$, preoperative [preop] CEA $>200 \mathrm{ng} / \mathrm{ml}$, and tumor size $>5 \mathrm{~cm}$ ) demonstrated a great variation in 5-year survival with $60 \%$ for a score of 0 and $20-14 \%$ for scores of $3-5 .{ }^{11}$ How can we improve results in patients with poor risk factors? Further regional therapy may be of benefit. In a randomized study comparing hepatic arterial infusion (HAI) plus systemic therapy (SYS) versus SYS alone after liver resection, in the subgroup of patients with poor clinical risk scores of 3-5, the 5-year survival was $60 \%$ for HAI + SYS versus $30 \%$ for SYS alone. ${ }^{12}$ The systemic therapy used in this trial was FU/LV. New agents possibly combined with targeted agents should also be studied as adjuvant therapy after resection to try to increase survival in these patients. In Viganò et al.'s paper the authors say there was a decrease in progression with bevacizumab (Bev) and cetuximab. It is not possible to draw this conclusion from a retrospective study when only $15 \%$ of patients received Bev, $6 \%$ cetuximab, and those receiving these drugs did not have a long follow-up (since these drugs were only recently approved). We would also need to see if patients given these new treatments had the same risk score as other patients not receiving these drugs to clearly say these treatments helped decrease progression.

\section{SHOULD ALL PATIENTS GET PREOP CHEMOTHERAPY}

It is not clear from this report how many patients had resectable disease prior to neoadjuvant therapy and what complications arose from the preop chemotherapy. An EORTC study reported an $8.1 \%$ increase in progression-free survival (PFS) with both preop and postop chemotherapy for patients with resectable disease. ${ }^{13}$ It is not clear from the EORTC study whether one could not obtain the same results with just postop chemotherapy. Two problems with preop chemotherapy are hepatic toxicity and shrinkage of some lesions so they are no longer visible and therefore difficult to resect. In an EORTC trial the complications were significantly increased after neoadjuvant therapy, 25 versus $15.9 \%$ in the control group $(p=0.04)$. Systemic chemotherapy increases steatosis, which increases the morbidity of surgery. ${ }^{14}$ In some patients oxaliplatin increases liver function tests and causes splenomegaly, and as the number of cycles increases problems including thrombocytopenia and portal hypertension increase. ${ }^{15,16}$ Steatohepatitis, which can be seen after treatment with irinotecan, can lead to increased mortality after liver resection. ${ }^{17}$ In a pooled analysis of two randomized studies of postoperative adjuvant SYS-FU/LV versus no further therapy after liver resection, the median PFS was 27.9 months for the treated group and 18.8 months for the surgery alone, similar to the EORTC study (24 vs 18 months for treated vs no chemotherapy), with a similar patient base, that is, low-risk patients with low number of metastases and similar low primary tumor stage. ${ }^{18}$ With the limits of cross-study comparisons, there were similar results for postop therapy with 5FU/LV versus preop and postop therapy with FOLFOX. Other data in favor of postop therapy includes randomized studies using postop HAI and SYS versus SYS after liver resection where there was a significant increase in PFS in three of the four large trials with HAI: 3-year PFS of 48-58 \% with HAI + SYS versus 23-39\% with SYS alone. ${ }^{19-22}$ The systemic therapy used in these studies was FU/LV. Some argue the same results could be obtained with modern chemotherapy. A retrospective review of 300 patients receiving HAI plus modern SYS versus modern SYS alone after liver resection, showed a significant increase in 3-year recurrence-free survival (RFS) with HAI + SYS $48 \%$ versus $25 \%$ for SYS alone..$^{23}$

\section{DISAPPEARING LESIONS}

For patients with unresectable disease, preoperative chemotherapy may decrease tumor size, decrease the number of lesions, and lead to disappearance of lesions. Some investigators have studied disappearing lesions and have documented that a number are still present at resection, and if not seen still have remaining tumor cells. ${ }^{24}$ For the complete responders in the Viganò study there is no mention of what was removed or if there were complete pathologic responses, but by 3 years $50 \%$ of these patients had recurrence. It would be interesting to know where the recurrences occurred. There is some data to suggest complete responses are more durable with HAI therapy with up 
to $87 \%$ true complete responses in two series using HAI therapy. 8,25

The authors are to be commended for working together and analyzing a large number of patients with hepatic colorectal metastases. The cooperation achieved among several medical institutions and multiple medical specialties is impressive. The authors documented the usefulness of hepatic resection even when patients have progressive disease on systemic chemotherapy, thus emphasizing the importance of regional therapy for oligometastatic disease.

\section{REFERENCES}

1. Viganò L, Capussotti L, Barroso E, Nuzzo G, Laurent C, Ijzermans JNM, et al. Progression while receiving preoperative chemotherapy should not be an absolute contraindication to liver resection for colorectal metastases. Ann Surg Oncol. 2012. doi: 10.1245/s10434-012-2382-7.

2. Adam R, Pascal G, Castaing D, Azoulay D, Delvart V, Paule B, et al. Tumor progression while on chemotherapy: a contraindication to liver resection for multiple colorectal metastases? Ann Surg. 2004;240:1052-61; discussion 1061-4.

3. Allen PJ, Kemeny N, Jarnagin W, DeMatteo R, Blumgart L, Fong Y. Importance of response to neoadjuvant chemotherapy in patients undergoing resection of synchronous colorectal liver metastases. J Gastrointest Surg. 2009;7:109-15.

4. Gallagher DJ, Zheng J, Capanu M, Haviland D, Paty P, Dematteo $\mathrm{RP}$, et al. Response to neoadjuvant chemotherapy does not predict overall survival for patients with synchronous colorectal hepatic metastases. Ann Surg Oncol. 2009;16:1844-51.

5. Gallagher DJ, Kemeny N. Second-line management of metastatic colorectal cancer. Clin Colorectal Cancer. 2008;7:25-32.

6. Ducreux M, Ychou M, Laplanche A, Gamelin E, Lasser P, Husseini $F$, et al. Hepatic arterial oxaliplatin infusion plus intravenous chemotherapy in colorectal cancer with inoperable hepatic metastases: a trial of the gastrointestinal group of the Federation Nationale des Centres de Lutte Contre le Cancer. $J$ Clin Oncol. 2005;23:4881-7.

7. Kemeny N, Huitzil M, Capanu M, Paty P, Fong Y, Schwartz L, et al. Conversion to resectability utilizing hepatic artery infusion plus systemic chemotherapy for the treatment of unresectable liver metastases from colorectal carcinoma. J Clin Oncol. 2009;27:3465-71.

8. Ito H, Kemeny NE, Gonen M, Allen PJ, Paty PB, Fong Y, et al. Biliary sclerosis following hepatic arterial infusion pump chemotherapy for patients with colorectal cancer liver metastasis: incidence, clinical features and risk factors. Ann Surg Oncol. 2012;19:1609-17.

9. Rougier P, Laplanche A, Hugier M, Hay JM, Olliver JM, Escat J, et al. Hepatic arterial infusion of floxuridine in patients with liver metastases from colorectal carcinoma: long-term results of a prospective randomized trial. Groupe d'Etudes et de Recherches des Tumeurs Hepatique. J Clin Oncol. 1992;10:112-8.

10. Nordlinger B, Guiget M, Vaillant JC, Balladu P, Boudjema K, Bachellier $\mathrm{P}$, et al. Surgical resection of colorectal carcinoma metastases to the liver. A prognostic scoring system to improve case selection, based on 1568 patients. Association Francaise de Chirurgie. Cancer. 1996;77:1254-62.

11. Fong Y, Fortner J, Sun RL, Brennan MF, Blumgart LH. Clinical score for predicting recurrence after hepatic resection for metastatic colorectal cancer: analysis of 1001 consecutive cases. Ann Surg. 1999;230:309-18; discussion 318-21.
12. Kemeny NE, Gonen M. Hepatic arterial infusion after liver resection. $N$ Engl J Med. 2005;352:734-5.

13. Nordlinger B, Sorbye H, Glimelius B, Poston GJ, Schlag PM, Rougier P, et al. Perioperative chemotherapy with FOLFOX4 and surgery versus surgery alone for resectable liver metastases from colorectal cancer (EORTC Intergroup trial 40983): a randomised controlled trial. Lancet. 2008;371:1007-16.

14. Kooby DA, Fong Y, Suriawinata A, Gonen M, Allen PJ, Klimstra DS, et al. Impact of steatosis on perioperative outcome following hepatic resection. J Gastrointest Surg. 2003;7:1034-44.

15. Overman MJ, Maru DM, Charnsangavej C, Loyer EM, Wang H, Pathak $\mathrm{P}$, et al. Oxaliplatin-mediated increase in spleen size as a biomarker for the development of hepatic sinusoidal injury. $J$ Clin Oncol. 2010;28:2549-55.

16. Slade JH, Alattar ML, Fogelman DR, Overman MJ, Agarwal A, Maru DM, et al. Portal hypertension associated with oxaliplatin administration: clinical manifestations of hepatic sinusoidal injury. Clin Colorectal Cancer. 2009;8:225-30.

17. Vauthey JN, Pawlik TM, Ribero D, Wu TT, Zorzi D, Hoff PM, et al. Chemotherapy regimen predicts steatohepatitis and an increase in 90-day mortality after surgery for hepatic colorectal metastases. J Clin Oncol. 2006;24(13):2065-72.

18. Mitry E, Fields AL, Bleiberg H, Labianca R, Portier G, Tu D, et al. Adjuvant chemotherapy after potentially curative resection of metastases from colorectal cancer: a pooled analysis of two randomized trials. J Clin Oncol. 2006;26:4906-11.

19. Kemeny MM, Adak S, Gray B, Macdonald JS, Smith T, Lipsitz $\mathrm{S}$, et al. Combined-modality treatment for resectable metastatic colorectal carcinoma to the liver: surgical resection of hepatic metastases in combination with continuous infusion of chemotherapy-an intergroup study. J Clin Oncol. 2002;20:1499-505.

20. Kemeny N, Huang Y, Cohen AM, Shi W, Conti JA, Brennan MF, et al. Hepatic arterial infusion of chemotherapy after resection of hepatic metastases from colorectal cancer. $N$ Engl $J$ Med. 1999;341:2039-48.

21. Lygidakis NJ, Sgourakis G, Vlachos L, Raptis S, Safioleas M, Boura P, et al. Metastatic liver disease of colorectal origin: the value of locoregional immunochemotherapy combined with systemic chemotherapy following liver resection: results of a prospective randomized study. Hepatogastroenterology. 2001;48: 1685-91.

22. Lorenz M, Muller HH, Schramm H, Gassel HJ, Rau HG, Ridwelski $\mathrm{K}$, et al. Randomized trial of surgery versus surgery followed by adjuvant hepatic arterial infusion with 5-fluorouracil and folinic acid for liver metastases of colorectal cancer: German Cooperative on Liver Metastases (Arbeitsgruppe Lebermetastasen). Ann Surg. 1998;228:756-62.

23. House MG, Kemeny NE, Gonen M, Fong Y, Allen PJ, Paty PB, et al. Comparison of adjuvant systemic chemotherapy with or without hepatic arterial infusional chemotherapy after hepatic resection for metastatic colorectal cancer. Ann Surg. 2011;254:851-6.

24. Benoist S, Brouquet A, Penna C, Julié C, El Hajjam M, Chagnon S, et al. Complete response of colorectal liver metastases after chemotherapy: Does it mean cure? J Clin Oncol. 2006;24:3939-45.

25. Elias D, Goere D, Boige V, Kohneh-Sharhi N, Malka D, Tomasic $\mathrm{G}$, et al. Outcome of posthepatectomy-missing colorectal liver metastases after complete response to chemotherapy: impact of adjuvant intra-arterial hepatic oxaliplatin. Ann Surg Oncol. 2007;14:3188-94.

26. Allen P, Nissan A, Picon A, Kemeny N, Dudrick P, Ben-Porat L, Espat J, et al. Technical complications and durability of hepatic artery infusion pumps for unresectable colorectal liver metastases: an institutional experience of 554 consecutive cases. $J$ Am Coll Surg. 2005;201:57-9. 